\title{
Evaluation of Fractionation Schemes in Breast Cancer Radiotherapy and Dosimetric Study of the Main Organs at Risk
}

\author{
Rodrigues M., ${ }^{\mathrm{a}, \mathrm{b}}$, , Teles P. ${ }^{\mathrm{b}, \mathrm{d}}$, Pirraco R..$^{\mathrm{b}}$, Oliveira D. ${ }^{\mathrm{b}}$, Costa P. ${ }^{\mathrm{b}}$ \\ ${ }^{a}$ Grupo de Proteção e Segurança Radiológica, Centro de Ciências e Tecnologias Nucleares, Instituto Superior \\ Técnico, Estrada Nacional 10 (km 139.7), 2695-066 Bobadela, Portugal \\ ${ }^{b}$ Júlio Teixeira S.A., Rua Fonte das Sete Bicas 170, Piso -1 4460 - 188 Senhora da Hora, Portugal \\ ${ }^{c}$ Departamento de Física e Astronomia da Faculdade de Ciências da Universidade do Porto, Rua do Campo Alegre, \\ $s / n, 4169-007$ Porto, Portugal \\ ${ }^{d}$ Instituto Português de Oncologia do Porto Francisco Gentil, EPE (IPO-Porto), Rua Dr. António Bernardino de \\ Almeida, 4200-072 Porto, Portugal \\ *mariajpereirarodrigues@gmail.com
}




\begin{abstract}
The purpose of this work was to evaluate the impact of different breast cancer radiotherapy regimens on the acceptance of the tolerance criteria of the main organs at risk, the heart, and the ipsilateral lung. In this context, the dosimetric treatment plans of 20 breast cancer patients treated at the Radiotherapy Service of Hospital de Braga (Portugal) were analyzed. The treatment planning system was the XiO (Elekta) and the dosimetric treatment plans were performed using with 3D-CRT technique (three-dimensional conformal radiation therapy) and the pencil beam algorithm for photon dose calculation. Two approaches to estimate the equivalence of different radiotherapy schedules have been proposed, the equivalent dose at 2 Gy per fraction model and the biologically effective dose model. These models showed that the conventional radiotherapy course to $50 \mathrm{~Gy}$ in 25 daily fractions is clinically equivalent to the hypofractionation course to $42.56 \mathrm{~Gy}$ in 16 daily fractions.

Obtained results showed that the tolerance criteria for the organs at risk, the heart and the ipsilateral lung, referring to the hypofractionation course to $42.56 \mathrm{~Gy}$ in 16 daily fractions, are more restrictive than the tolerance criteria of conventional regimen. This means that if the same setup and the same dose coverage in the planning target-volume are used, the tolerance criteria for the organs at risk of hypofractionation regime are more difficult to attain. These results can assist radiation oncologists in the evaluation of radiotherapy prescription doses for breast cancer, in compliance with the principles of radiation protection.
\end{abstract}

Keywords: External radiotherapy, breast cancer, fractionation, tolerance criteria, organs at risk, radiation protection 


\section{INTRODUCTION}

Early-stage breast cancer patients can benefit from post lumpectomy radiation therapy. It has been shown that post lumpectomy radiotherapy is associated with a promising long-term local control with similar survival outcomes to mastectomy. Currently, breast cancer standard management recommends treatment with photon external beam radiotherapy by irradiating the entire breast with a total dose of 50 Gy in fractional doses of 2 Gy, during five working weekdays (conventional fractionation). Frequently, an additional 10 Gy-20 Gy dose has been used to boost the tumor excision site, resulting in an overall treatment time of 5 to 7 weeks [1].

The linear quadratic model is of paramount importance in radiotherapy and radiobiology, as it provides a simple relation between cell survival and delivered dose, for which it is abundantly used to predict in vivo and in vitro biological responses to ionizing radiation. It takes the form:

$$
S=e^{-\alpha D-\beta D^{2}}
$$

Where $D$ is the dose in Gy, $\alpha$ a linear parameter $\left(\mathrm{Gy}^{-1}\right)$ and $\beta$ a quadratic parameter $\left(\mathrm{Gy}^{-2}\right)$. These parameters define two response regions. The linear term in $\alpha$ dominates in the low dose region, whereas the curvature in higher doses is due to the quadratic term in $\beta$, leading to the wellknown "shouldered" response curve. The shape of this curvature is often defined in terms of the $\alpha / \beta$ ratio which has units of Gy. Typically, high values of the $\alpha / \beta$ ratio lead to pronounced linear responses while low ratios lead to pronounced curvatures [2].

Results in the literature suggest that the $\alpha / \beta$ ratio of breast cancer is in the range of $3-5 \mathrm{~Gy}$, and although it is necessary to recognize that the $\alpha / \beta$ ratio may vary according to the different biological subtypes of breast cancer, the linear-quadratic model suggests that, when the $\alpha / \beta$ ratio of the tumor is the same or less than that of the critical normal tissue, a larger dose per fraction (hypofractionation), with a modest decrease in total dose, may be equally or potentially more effective than conventional fractionation $[3,4]$. An estimate of 4 Gy for $\alpha / \beta$ ratio has been already reported for the fractionation sensitivity of breast cancer [5]. The low estimated $\alpha / \beta$ ratio for breast 
cancer means that it is probably as sensitive to fraction size as is dose-limiting normal tissue. In this sense, hypofractionation for breast cancer may be advantageous $[3,5]$.

Retrospective studies of hypofractionated radiotherapy in early breast cancer suggest satisfactory outcomes in tumor control and late adverse effects if modest increases in fraction sizes are combined with appropriate downward adjustments to total dose. For example, the results of a Canadian randomized trial (ONTARIO trial) testing 42.56 Gy in 16 fractions against 50 Gy in 25 fractions are consistent with these findings [6].

Novel radiation therapy techniques can potentially optimize the protection of organs at risk (OAR). Despite this, heart and lung doses remain important dosimetric surrogates for long term effects, and hence influence clinical decision-making in adjuvant radiotherapy for breast cancer. Breast cancer radiotherapy affects surrounding healthy tissue and can lead to persistent edema, hyperpigmentation, fibrosis and pneumonitis, or even more severe late effects, like cardiac toxicity and secondary lung cancer $[7,8]$. The probability of long-term side effects generally depends on the dose per fraction, time interval between fractions, total radiation dose, irradiated volume, dosimetric parameters, cardiotoxicity of concomitant therapies and patient-specific risk factors [8]. Taking this into account, it is important to analyze different dose delivery regimens which can optimize treatment while sparing OARs.

The purpose of this work was to evaluate the impact of different radiotherapy schedules in breast cancer treatments on the fulfillment of the tolerance criteria of the main OARs, the heart and ipsilateral lung. In this context, the dosimetric treatment planning data of left-sided breast cancer patients treated at the Radiotherapy Service of Hospital de Braga (Portugal) in 2018 were analyzed and treated.

\section{MATERIALS AND METHODS}

Patient and treatment planning data were collected from the electronic medical records using MOSAIQ (version 2.41, Elekta AB, Stockholm, Sweden) [9] and the database of the medical physics service. Collected information included the total number of treated patients; the first and several radiotherapy treatment schedules; and location of the tumor. The sample was distributed 
according to age group and the fractionation treatment schedules. The data were randomly anonymized in full compliance with EU and national (Portuguese) regulation.

To evaluate the potential clinical outcome of the fractionation treatment schedules, the linearquadratic model based biological effectiveness of a given fractionation scheme size was used. This is related to the $\alpha / \beta$ ratio and may be expressed in terms of the biologically effective dose (BED) [4]:

$$
B E D=D\left(1+\frac{d}{\alpha / \beta}\right)-K\left(T-T_{d}\right)
$$

where $\mathrm{D}$ is the total dose delivered during the treatment (expressed in Gy), obtained by multiplying the total number of treatment fractions (n) by the dose per fraction (d); $\alpha$ and $\beta$ are the radiosensivity coefficients of the linear-quadratic model, expressed in $\mathrm{Gy}^{-1}$ e $\mathrm{Gy}^{-2}$, respectively; $\mathrm{T}$ is the overall treatment time; $\mathrm{T}_{\mathrm{d}}$ is the delay time to onset of accelerated repopulation. Finally, $\mathrm{K}$ (expressed in Gy/day) is the biological dose per day required to compensate for ongoing tumor cell repopulation, calculated based on $\mathrm{T}_{\text {pot }}$ (potential doubling time) and $\alpha$ (radiosensitivity coefficient), in the following way:

$$
K=\frac{\ln 2}{\alpha T_{p o t}}
$$

Reference values in the literature state that $T_{\text {pot }}=14$ days and $\alpha=0.08$ [5]. This equation also a corrects for the repopulation effect, which must be considered for post-operative breast tumors treated with radiotherapy because surgical resection can leave behind viable cells which, because they are well vascularized, are capable of rapid growth [5].

In this work, an effective doubling time $\mathrm{T}_{\text {eff }}$ of 26 days to start immediately after surgery is taken from the literature $[5,10]$ and $\mathrm{T}_{\mathrm{d}}$ is considered as zero. 
BED can be used to equate or compare different fractionation schedules. However, a more practical alternative is to convert the BED values to equivalent total doses. This can be done by assuming that two different treatments ( 1 and 2$)$ with different fractionations $\left(d_{1}\right.$ is the dose per fraction in treatment 1 , and $\mathrm{d}_{2}$ the same in treatment 2 ), give the same BED:

$$
B E D_{1}=B E D_{2} \Leftrightarrow D_{1}\left(1+\frac{d_{1}}{\alpha / \beta}\right)=D_{2}\left(1+\frac{d_{2}}{\alpha / \beta}\right)
$$

which can then be interpreted according to clinical experience. Considering treatment two as 2 Gy fractions, we can define the dose equivalent to $2 \mathrm{~Gy}$ per fraction $\left(\mathrm{EQD}_{2}\right)$ [3]:

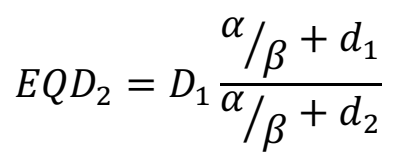

In the first part of this study, a statistical analysis of the patients treated at the Radiotherapy Service of Hospital de Braga (Portugal) in 2018 was performed. Then, for left sided breast cancer patients in the database, the BED for the two main fractionation schemes was determined and the results compared.

In the second part, 20 female patients treated with adjuvant radiotherapy for left-sided breast cancer were randomly selected from the database. Left-sided breast cancer was chosen because treatment contributes to higher radiation doses to the heart.

Of these 20 patients, 10 were treated with conventional radiotherapy schedules of 50 Gy in 25 daily fractions, and the other 10 patients were treated with a hypofractionation course of 42.56 Gy in 16 daily fractions. All patients performed a CT scan in the supine position using immobilization support, with both arms above the head.

The radiation treatment planning system (RTPS) was the XiO (version 4.62, Elekta AB) [11] using 3-dimensional conformal radiation therapy (3D-CRT) in a 6MV Varian 6EX linear accelerator with a multileaf collimator. 
To evaluate the 3D dose distributions and the dose-volume histograms (DVH) of the OAR, the parameters shown in table 1 were used. These criteria vary according to the type of fractionation regime used in the radiotherapy treatment.

Table 1: Tolerance criteria used to evaluate the RTP [12-14].

\begin{tabular}{cc|c}
\hline Organs at Risk & $\begin{array}{c}\text { Conventional Fractionation } \\
\mathbf{5 0} \mathbf{~ G y} / \mathbf{2 5} \text { fractions }\end{array}$ & $\begin{array}{c}\text { Hypofractionation } \\
\mathbf{4 2 . 5 6 G y} / \mathbf{1 6} \text { fractions }\end{array}$ \\
\hline Heart & $\mathrm{V}_{25 \mathrm{~Gy}} \leq 10 \%$ & $\mathrm{~V}_{16 \mathrm{~Gy}} \leq 5 \%$ \\
& Mean Dose $\leq 5 \mathrm{~Gy}$ & Mean Dose $\leq 3.2 \mathrm{~Gy}$ \\
\hline Ipsilateral Lung & $\mathrm{V}_{20 \mathrm{~Gy}} \leq 20 \%$ & $\mathrm{~V}_{12 \mathrm{~Gy}} \leq 17 \%$ \\
& & $\mathrm{~V}_{16 \mathrm{~Gy}} \leq 15 \%$ \\
\hline
\end{tabular}

After the dosimetric evaluation of the original treatment plans, these plans were converted in the opposite fractionation scheme, that is, plans with a prescribed dose of 50Gy in 25 fractions were converted to plans with a prescribed dose of 42.56Gy in 16 fractions, while plans with a prescribed dose of $42.56 \mathrm{~Gy}$ in 16 fractions were converted to plans with a prescribed dose of $50 \mathrm{~Gy}$ in 25 fractions. These new treatment plans are called rescale plans and were not used in the treatment of patients, they only served to perform the dosimetric evaluation using the parameters and tolerance criteria shown in table 1.

The conversion of treatment plans was carried out using the Rescale tool from the XiO planning system, which makes a direct conversion of the doses of the two treatment prescriptions using the same configuration of the treatment fields. 


\section{RESULTS AND DISCUSSION}

In the first part of this work, a total of 1689 patients were treated at the Radiotherapy Service of Hospital de Braga (Portugal) in 2018, 733 female (43.4\%) and 956 male (56.6\%). 88\% of patients (corresponding to 1489) performed radiotherapy for the first time, while 12\% (corresponding to 200) were at several radiotherapy treatments.

A total of 393 patients were treated with breast radiotherapy, 391 females (99.5\%) and 2 males $(0.5 \%)$. Of these, 207 patients treated the left-sided breast $(52.7 \%), 183$ the right-sided breast $(46.6 \%)$ and 3 both breasts simultaneously (0.7\%). Median age at time of radiotherapy was 59 years old (range: 28-96).

Patients belonging to the 45-54 age group are those who have a greater representation in the sample (29\%). Next are the patients belonging to the age group 55-64 years and 65-74 years, respectively, with each representing $22 \%$ of the sample. The $18-34$ age group is the one with the lowest representation in the sample $(2 \%)$.

The most frequent fractionation schemes were the conventional fractionation course to $50 \mathrm{~Gy}$ in 25 daily fractions ( $n=125$ for the left breast, $n=106$ for the right breast, and $n=3$ for both breasts) and the hypofractionation course to 42.56 Gy in 16 daily fractions ( $n=82$ for the left breast, $n=77$ for the right breast, and $n=0$ for both breasts), as shown in figure 1 . It can be seen that even if hypofractionation has become more common, conventional fractionation is still the most used schedule.

The conventional fractionation has an average radiotherapy time of 33 days, while the hypofractionation course has an average duration of 22 days. 


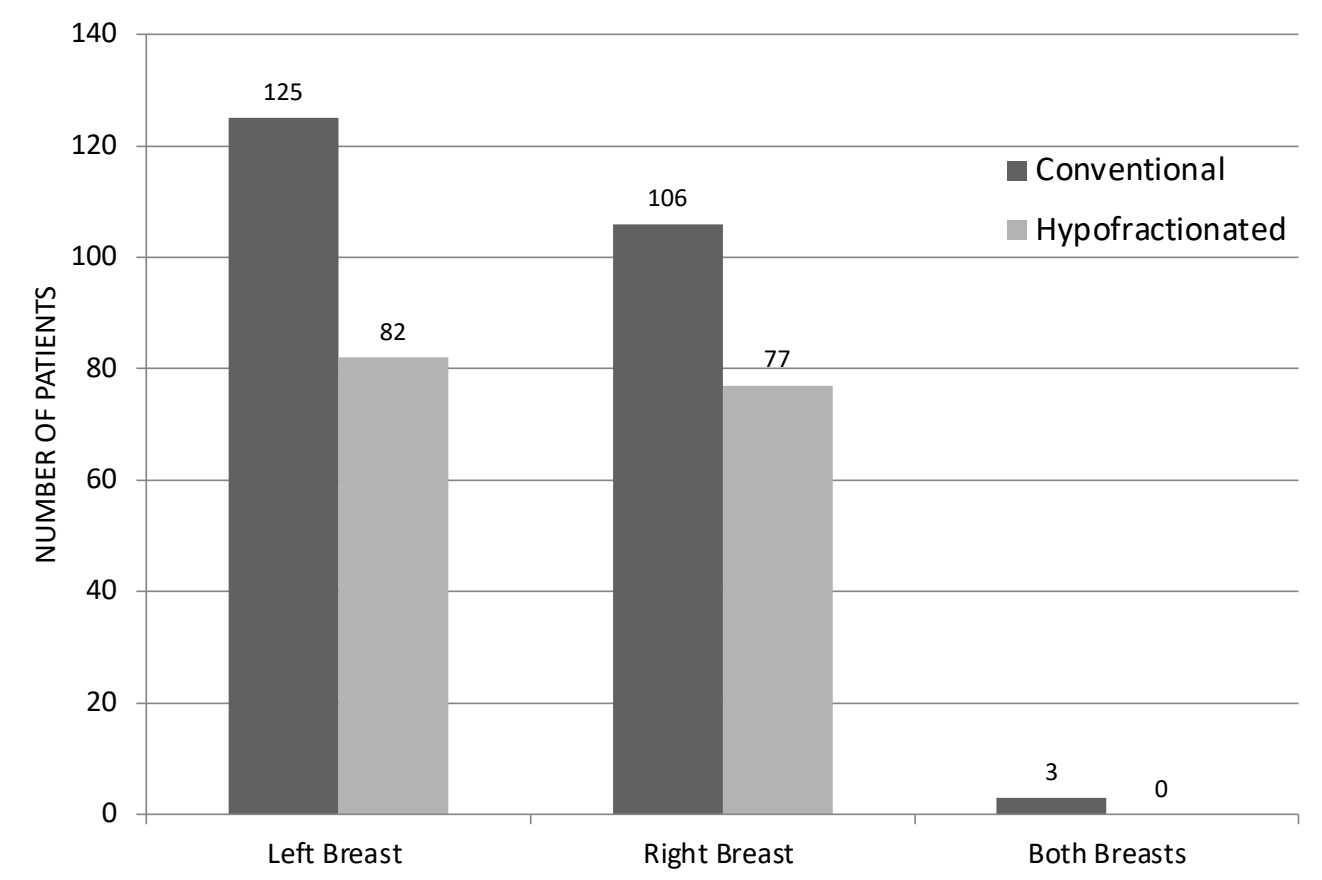

Figure 1: Left, right and both breast cancer treatments by fractionation scheme at the Hospital of Braga, Portugal.

In Table 2, BED calculations are shown for either breast cancer or normal tissues (fibrosis and erythema), for both conventional and hypofractionation schemes. The BED calculation for breast tumor shown in the first column includes the appropriate correction for repopulation. For the normal tissues no correction for repopulation was assessed.

Table 2: BED calculations for tumor control, late fibrosis, and erythema in the two main fractionation schemes.

\begin{tabular}{|c|c|c|c|}
\hline $\begin{array}{c}\text { Fractionations } \\
\text { Schemes }\end{array}$ & $\begin{array}{c}\text { BED }(\mathbf{G y}) \\
\text { Tumor control } \\
\alpha / \beta=4 \mathbf{G y} \\
\end{array}$ & $\begin{array}{c}\text { BED (Gy) } \\
\text { Late Fibrosis } \\
\alpha / \beta=2.5 \mathrm{~Gy}\end{array}$ & $\begin{array}{l}\text { BED (Gy) } \\
\text { Erythema } \\
\alpha / \beta=8 \mathrm{~Gy}\end{array}$ \\
\hline $\begin{array}{c}\text { Conventional } \\
50 \mathrm{~Gy} / 25 \text { fractions }\end{array}$ & 54.6 & 90 & 62.5 \\
\hline $\begin{array}{c}\text { Hypofractionation } \\
42.56 \mathrm{~Gy} / 16 \\
\text { fractions } \\
\left(\mathrm{EQD}_{2}=47,2 \mathrm{~Gy} \text { for }\right. \\
\alpha / \beta=4 \mathrm{~Gy})\end{array}$ & 57.3 & 87.8 & 56.7 \\
\hline
\end{tabular}


The value of the $\alpha / \beta$ ratio used for tumor control was $4 \mathrm{~Gy}$. Analyzing the results for BED values of the tumor control, it is possible to verify that the BED value for the hypofractionation scheme is 57.3 Gy, which is slightly higher than the BED value for the conventional fractionation scheme of 54.6 Gy. According to this calculation, the BED value for the hypofractionated scheme favors increased tumor control.

According to the literature, breast fibrosis (late effect) is associated with an $\alpha / \beta$ ratio of $2.5 \mathrm{~Gy}$, while erythema (acute effect) is associated with an $\alpha / \beta$ ratio of 8 Gy [10]. The obtained results show that the BED values calculated for normal tissues using the hypofractionated treatment scheme are lower than the values obtained in the conventional treatment scheme. These results favor the use of hypofractionated scheme, as it causes less side effects to healthy breast tissues.

The results presented in table 2 agree with the results presented by the Canadian study by Whelan TJ et al. [6], both about tumor control and the expected effects on healthy breast tissues. Results of this trial demonstrate that a shorter fractionation schedule of 42.53 Gy in 16 fractions over 22 days is as effective as the more traditional schedule of 50 Gy in 25 fractions over 33 days in terms of preventing recurrence of breast cancer. The rates of local recurrence at 5 years were low and similar in both treatment arms. Regarding normal tissues, the results of the Canadian study demonstrated that the incidence of late radiation toxicity on skin and subcutaneous tissue was uncommon in both treatment regimes, although patients treated with hypofractionation radiotherapy fared about $5 \%$ better. Given that most of the toxic effects of radiation therapy would be expected by 5 years, further differences between groups in skin and subcutaneous tissue toxicity are unlikely to occur with longer follow-up.

The BED (equation 3) for the two fractionation schemes was determined for different values of $\alpha / \beta$, the results of which are given in figure 2 .

As can be seen from figure 2, the two fractionation schemes have similar BED values until $\sim 2 \mathrm{~Gy}$, after which the BED of the hypofractionation scheme diverges to lower values than the conventional one. Considering that the lowest value for $\alpha / \beta$ is $2.5 \mathrm{~Gy}$ in the late fibrosis case, this means that in practical terms the BED will always be slightly smaller in the hypofractionation scheme. 
The dose equivalent to 2 Gy per fraction $\left(\mathrm{EQD}_{2}\right)$, as given in equation 4 , was calculated both for the conventional and hypofractionation schemes, allowing for the estimation of the equivalence of the two fractionation schemes used in radiotherapy treatments.

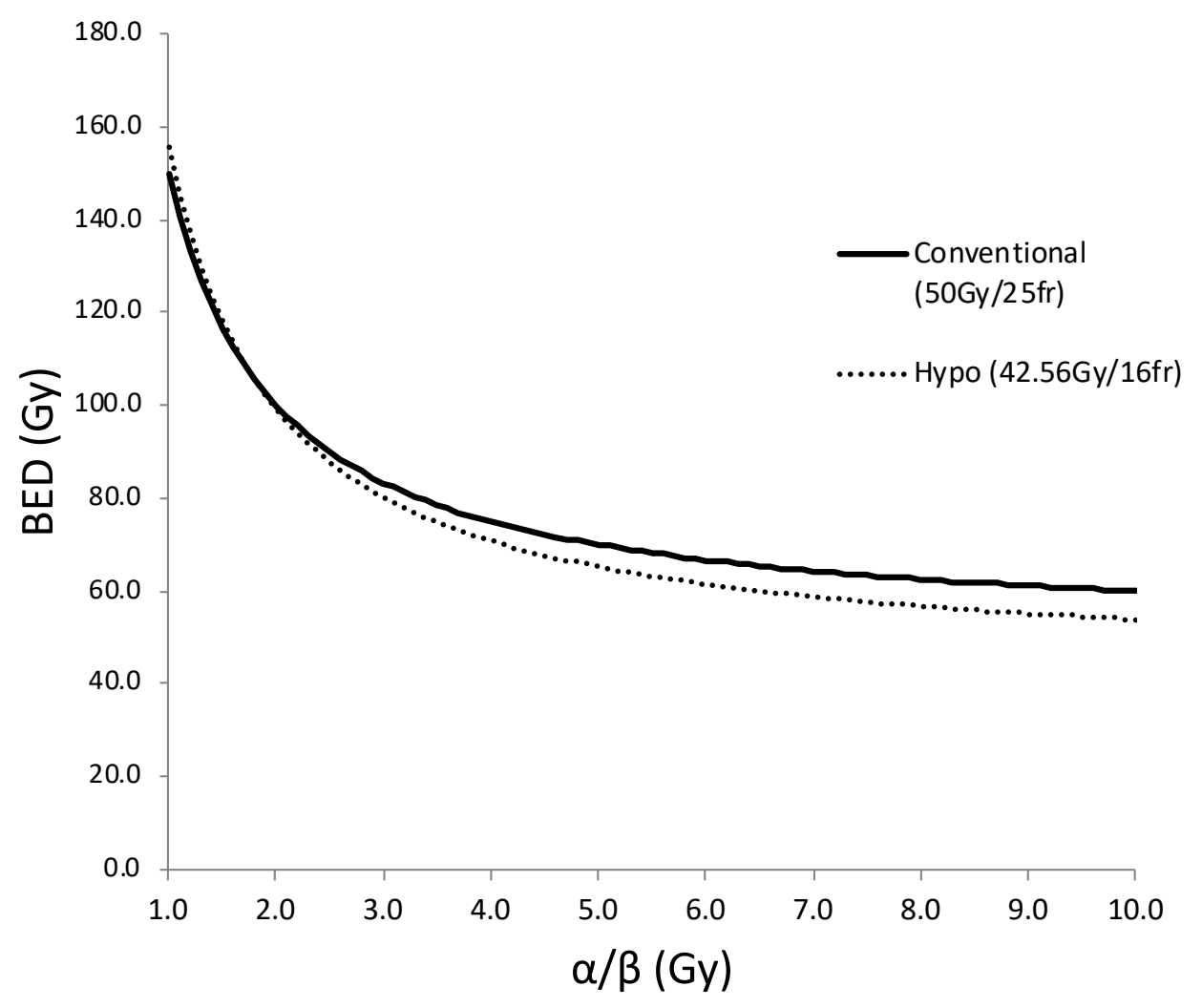

Figure 2: BED for the two fractionation schemes as a function of the $\alpha / \beta$ ratio

Results are shown in figure 3. It is possible to verify that, as above, the lower the value of the $\alpha / \beta$ ratio, the more equivalent are the two fractionation schemes. That is, for an $\alpha / \beta=2$ Gy, the $\mathrm{EQD}_{2}$ value of the hypofractionation scheme is $49.6 \mathrm{~Gy}$, this value being the closest to the $50 \mathrm{~Gy}$ value, corresponding to the conventional fractionation scheme.

Based on this information and according to the results presented, it can be concluded that the hypofractionation course to $42.56 \mathrm{~Gy}$ in 16 fractions is a good candidate for the treatment of breast cancer, as this tumor has low $\alpha / \beta$ ratio values in relation to other types of tumors, where the typical 
value is around $10 \mathrm{~Gy}$. For this reason, for the values of the $\alpha / \beta$ ratio presented, the $\mathrm{EQD}_{2}$ curve of the hypo fractioned scheme approaches the curve of the conventional treatment scheme, which indicates that the two treatment schemes are clinically equivalent.

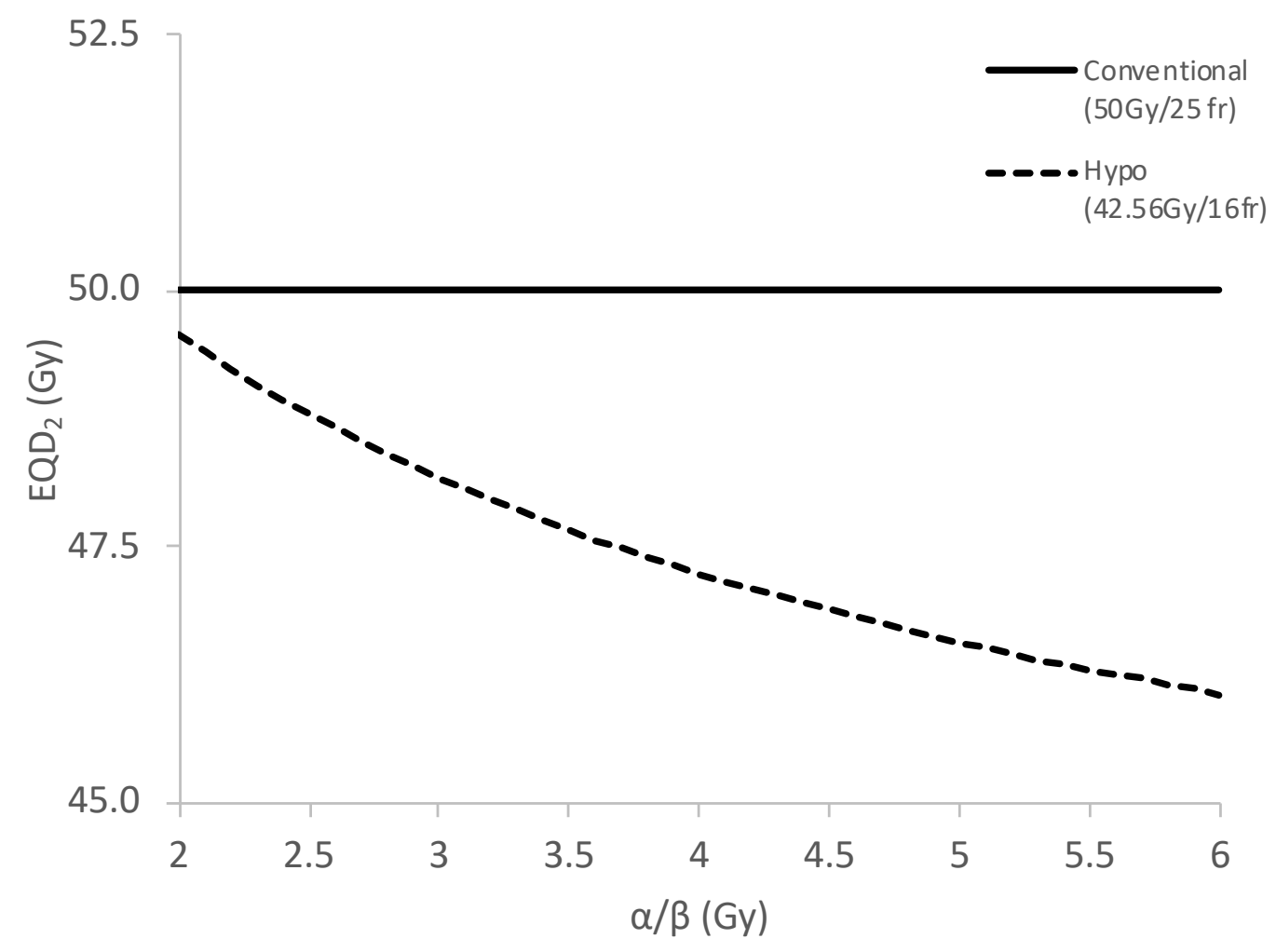

Figure 3: $E Q D_{2}$ values as a function of the $\alpha / \beta$ ratio

As for the second part of this work, results obtained in the dosimetric analysis of the treatment plans for 20 randomly selected treatments of left-sided breast cancer in females (10 with $50 \mathrm{~Gy} / 25 \mathrm{fr}$ treatment, and 10 with $42.56 \mathrm{~Gy} / 16 \mathrm{fr}$ treatment) are shown in tables 3 and 4.

Starting by analyzing the results presented in table 3 , it is possible to observe that for all original treatment plans with a conventional fractionation regime, all dosimetric parameters evaluated meet the tolerance criteria of the respective organs at risk. 
The same is not verified when these plans were converted to a 42.56 Gy hypofractionation scheme in 16 fractions. In this case, several dosimetric parameters exceed the tolerance criteria. For the heart, $60 \%$ of the sample does not meet the criteria (plans 1, 3, 5, 6, 9 and 10), and for the lung, $40 \%$ of the sample does not meet the criteria (plans 1, 4, 8 and 9).

Regarding the results presented in table 4, it is possible to observe that, except for plan 13, all the other original treatment plans composed of a hypofractionation scheme of 42.56 Gy in 16 fractions, fulfill all the tolerance criteria. In the case of plan 13, the dosimetric parameter for the lung exceeds the tolerance criteria, that is, $\mathrm{V}_{12 \mathrm{~Gy}}=17.7 \%$ and $\mathrm{V}_{16 \mathrm{~Gy}}=15.6 \%$.

When converting the original plans shown in table 4 to a conventional 50 Gy fractionation scheme in 25 fractions, all dosimetric parameters for both heart and ipsilateral lung meet the respective criteria.

Obtained results showed that the tolerance criteria for the organs at risk, the heart and the ipsilateral lung, referring to the hypofractionation course to $42.56 \mathrm{~Gy}$ in 16 daily fractions, are more restrictive than the tolerance criteria of conventional radiotherapy. This means that if the same setup and the same dose coverage in the planning target-volume are used, the tolerance criteria for the organs at risk of hypofractionation regime are more difficult to attain.

\section{CONCLUSION}

Breast cancer is the second most common cancer worldwide. In women, it has the highest incidence among tumors.

In this work, it was possible to verify that in the study sample referring to patients who performed radiotherapy treatment at Hospital de Braga (Portugal) in 2018, breast cancer was the one that had the highest prevalence in female patients, representing $61 \%$ of all the cases. Patients aged 45-54 years were those who with a greater representation in the sample (29\%).

According to the results, $60 \%$ of the radiotherapy treatment plans were carried out with a conventional fractionation course to 50 Gy in 25 fractions, while the remaining $40 \%$ were carried out with a hypofractionation scheme, the most used being 42.56 Gy in 16 fractions. 
The low value of the $\alpha / \beta$ ratio for breast cancer, currently estimated at $4 \mathrm{~Gy}$, means that probably the tumor tissue is as sensitive to the dose delivered per fraction as the normal tissue that limits the dose, which indicates that hypofractionation can be advantageous in breast cancer radiotherapy treatments.

Comparing the conventional fractionation course to 50 Gy in 25 fractions with the hypofractionation course to 42.56 Gy in 16 fractions, by calculating the BED and EQD2 it was possible to verify that the two regimens are clinically equivalent, with hypofractionation increasing tumor control, providing less late toxicity.

Another advantage of using hypofractionation radiotherapy is related to the fact that these treatments have a shorter duration, which allows to treat a larger number of patients, improve their quality of life as they finish treatment faster and still reduce the associated costs.

With regard to the dosimetric study performed, dosimetric parameters commonly used in clinical practice were analyzed, which play a role as clinical predictors of toxicity to the organs at risk.

Through the obtained results it was possible to conclude that the tolerance criteria, for the heart and the lung, referring to the hypofractionation course to $42.56 \mathrm{~Gy}$ in 16 fractions are more restrictive than the tolerance criteria of the conventional radiotherapy. That is, when the plans treated with the conventional scheme were converted to the hypofractionation scheme, $60 \%$ of the sample does not meet the tolerance criteria for heart, while $40 \%$ does not meet the tolerance criteria for lung. This result means that using the same setup and obtaining the same dose coverage in the planning target-volume, the tolerance criteria for the organs at risk of hypofractionation regime are more difficult to accomplish.

The dosimetric study was carried out on the treatment plans for single left-sided breast, since this treatment contributes to higher doses in the heart compared to right-sided breast treatments. However, when we evaluate breast treatment plans where it is also necessary to irradiate the axillary region, the supraclavicular region or the internal mammary chain, the doses received, namely by the lung, increase considerably. Thus, in these treatment plans it is more difficult to meet the tolerance criteria of the organs at risk for hypofractionation regimes.

These results can assist radiation oncologists in the evaluation of radiotherapy prescription doses for breast cancer, in compliance with the principles of radiation protection. 
Table 3: Results of the dosimetric evaluation. The original treatment plans have a prescribed dose of $50 \mathrm{~Gy}$ in 25 fractions and the rescale plans has a prescribed dose of $42.56 \mathrm{~Gy}$ in 16 fractions. A Yes $(\mathrm{Y})$ or No $(\mathrm{N})$ is placed whenever the value meets or does not meet the prescribed criteria.

\begin{tabular}{|c|c|c|c|c|c|c|c|c|c|c|c|c|c|c|}
\hline \multirow[b]{3}{*}{ Plan ID } & \multicolumn{8}{|c|}{ Heart } & \multicolumn{6}{|c|}{ Ipsilateral Lung } \\
\hline & \multicolumn{4}{|c|}{$\begin{array}{l}\text { Original Treatment Plan } \\
50 \mathrm{~Gy} / 25 \text { fractions }\end{array}$} & \multicolumn{4}{|c|}{$\begin{array}{c}\text { Rescale Plan } \\
42.56 \mathrm{~Gy} / 16 \text { fractions }\end{array}$} & \multicolumn{2}{|c|}{$\begin{array}{l}\text { Original Treatment } \\
\text { Plan } \\
50 \mathrm{~Gy} / 25 \text { fractions }\end{array}$} & \multicolumn{4}{|c|}{$\begin{array}{c}\text { Rescale Plan } \\
42.56 \mathrm{~Gy} / 16 \text { fractions }\end{array}$} \\
\hline & $\mathrm{V}_{25 \mathrm{G}_{\mathrm{y}}} \leq 10 \%$ & Pass? & $\mathrm{D}_{\text {mean }} \leq 5 \mathrm{~Gy}$ & Pass? & $\mathrm{V}_{16 G_{\mathrm{y}}} \leq 5 \%$ & Pass? & $\mathrm{D}_{\text {mean }} \leq 3.2 \mathrm{~Gy}$ & Pass? & $\mathrm{V}_{20 \mathrm{~Gy}} \leq 20 \%$ & Pass? & $\mathrm{V}_{12 \mathrm{~Gy}} \leq 17 \%$ & Pass? & $\mathrm{V}_{16 \mathrm{CGy}_{\mathrm{y}}} \leq 15 \%$ & Pass? \\
\hline 1 & 7.1 & $\mathrm{Y}$ & 5.0 & $\mathrm{Y}$ & 8.2 & $\mathrm{~N}$ & 4.3 & $\mathrm{~N}$ & 16.8 & $\mathrm{Y}$ & 19.1 & $\mathrm{~N}$ & 17.2 & $\mathrm{~N}$ \\
\hline 2 & 2.5 & Y & 2.4 & $\mathrm{Y}$ & 3.2 & Y & 2.0 & $\mathrm{Y}$ & 12.3 & Y & 14.7 & Y & 12.8 & Y \\
\hline 3 & 5.3 & Y & 4.2 & Y & 6.3 & $\mathrm{~N}$ & 3.6 & $\mathrm{~N}$ & 15.0 & Y & 17.0 & Y & 15.0 & $\mathrm{Y}$ \\
\hline 4 & 0.6 & Y & 1.7 & Y & 0.9 & Y & 1.5 & $\mathrm{Y}$ & 16.8 & Y & 19.6 & $\mathrm{~N}$ & 17.3 & $\mathrm{~N}$ \\
\hline 5 & 4.9 & Y & 4.1 & Y & 6.0 & $\mathrm{~N}$ & 3.5 & $\mathrm{~N}$ & 8.6 & Y & 10.4 & $\mathrm{Y}$ & 8.9 & Y \\
\hline 6 & 7.4 & Y & 4.9 & Y & 9.1 & $\mathrm{~N}$ & 4.2 & $\mathrm{~N}$ & 13.2 & Y & 15.7 & $\mathrm{Y}$ & 13.7 & Y \\
\hline 7 & 3.0 & $\mathrm{Y}$ & 3.3 & $\mathrm{Y}$ & 3.8 & Y & 2.8 & Y & 8.2 & $\mathrm{Y}$ & 9.9 & Y & 8.4 & Y \\
\hline 8 & 3.1 & Y & 3.1 & Y & 4.0 & Y & 2.6 & $\mathrm{Y}$ & 20.0 & Y & 22.9 & $\mathrm{~N}$ & 20.7 & $\mathrm{~N}$ \\
\hline 9 & 5.5 & Y & 4.3 & Y & 6.8 & $\mathrm{~N}$ & 3.6 & $\mathrm{~N}$ & 17.4 & Y & 19.9 & $\mathrm{~N}$ & 17.8 & $\mathrm{~N}$ \\
\hline 10 & 5.4 & Y & 4.2 & Y & 6.4 & $\mathrm{~N}$ & 3.6 & $\mathrm{~N}$ & 10.0 & Y & 11.3 & $\mathrm{Y}$ & 10.2 & $\mathrm{Y}$ \\
\hline
\end{tabular}


Table 4: Results of the dosimetric evaluation. The original treatment plans have a prescribed dose of 42.56 Gy in 16 fractions and the rescale plans has a prescribed dose of $50 \mathrm{~Gy}$ in 25 fractions. A Yes (Y) or No (N) is placed whenever the value meets or does not meet the prescribed criteria.

\begin{tabular}{|c|c|c|c|c|c|c|c|c|c|c|c|c|c|c|}
\hline \multirow[b]{3}{*}{ Plan ID } & \multicolumn{8}{|c|}{ Heart } & \multicolumn{6}{|c|}{ Ipsilateral Lung } \\
\hline & \multicolumn{4}{|c|}{$\begin{array}{c}\text { Original Treatment Plan } \\
42.56 \mathrm{~Gy} / 16 \text { fractions }\end{array}$} & \multicolumn{4}{|c|}{$\begin{array}{c}\text { Rescale Plan } \\
50 \text { Gy/25 fractions }\end{array}$} & \multicolumn{4}{|c|}{$\begin{array}{c}\text { Original Treatment Plan } \\
42.56 \mathrm{~Gy} / 16 \text { fractions }\end{array}$} & \multicolumn{2}{|c|}{$\begin{array}{c}\text { Rescale Plan } \\
50 \mathrm{~Gy} / 25 \text { fractions }\end{array}$} \\
\hline & $\mathrm{V}_{16 \mathrm{~Gy}} \leq 5 \%$ & Pass? & $\mathrm{D}_{\text {mean }} \leq 3.2 \mathrm{~Gy}$ & Pass? & $\mathrm{V}_{25 \mathrm{~Gy}} \leq 10 \%$ & Pass? & $\mathrm{D}_{\text {mean }} \leq 5 \mathrm{~Gy}$ & Pass? & $\mathrm{V}_{12 \mathrm{~Gy}} \leq 17 \%$ & Pass? & $\mathrm{V}_{16 \mathrm{~Gy}} \leq 15 \%$ & Pass? & $\mathrm{V}_{20 \mathrm{~Gy}} \leq 20 \%$ & Pass? \\
\hline 11 & 4.1 & $\mathrm{Y}$ & 2.5 & $\mathrm{Y}$ & 3.3 & $\mathrm{Y}$ & 2.9 & $\mathrm{Y}$ & 16.6 & $\mathrm{Y}$ & 14.6 & $\mathrm{Y}$ & 14.2 & $\mathrm{Y}$ \\
\hline 12 & 4.9 & $\mathrm{Y}$ & 3.1 & $\mathrm{Y}$ & 4.0 & $\mathrm{Y}$ & 3.6 & $\mathrm{Y}$ & 12.8 & $\mathrm{Y}$ & 11.3 & $\mathrm{Y}$ & 10.9 & $\mathrm{Y}$ \\
\hline 13 & 1.8 & $\mathrm{Y}$ & 1.5 & $\mathrm{Y}$ & 1.1 & $\mathrm{Y}$ & 1.8 & $\mathrm{Y}$ & 17.7 & $\mathrm{~N}$ & 15.6 & $\mathrm{~N}$ & 15.1 & $\mathrm{Y}$ \\
\hline 14 & 5.0 & $\mathrm{Y}$ & 2.8 & $\mathrm{Y}$ & 3.9 & $\mathrm{Y}$ & 3.3 & $\mathrm{Y}$ & 17.0 & $\mathrm{Y}$ & 15.0 & $\mathrm{Y}$ & 14.8 & $\mathrm{Y}$ \\
\hline 15 & 4.9 & $\mathrm{Y}$ & 2.8 & $\mathrm{Y}$ & 3.8 & $\mathrm{Y}$ & 3.3 & $\mathrm{Y}$ & 13.8 & $\mathrm{Y}$ & 11.6 & $\mathrm{Y}$ & 11.0 & $\mathrm{Y}$ \\
\hline 16 & 0.9 & $\mathrm{Y}$ & 1.3 & Y & 0.5 & Y & 1.6 & $\mathrm{Y}$ & 14.4 & $\mathrm{Y}$ & 12.5 & $\mathrm{Y}$ & 12.1 & $\mathrm{Y}$ \\
\hline 17 & 2.8 & Y & 2.0 & Y & 2.3 & Y & 2.3 & $\mathrm{Y}$ & 15.1 & $\mathrm{Y}$ & 13.2 & $\mathrm{Y}$ & 12.8 & $\mathrm{Y}$ \\
\hline 18 & 3.8 & $\mathrm{Y}$ & 2.2 & Y & 3.1 & $\mathrm{Y}$ & 2.6 & $\mathrm{Y}$ & 11.1 & $\mathrm{Y}$ & 9.8 & $\mathrm{Y}$ & 9.5 & $\mathrm{Y}$ \\
\hline 19 & 4.9 & $\mathrm{Y}$ & 2.7 & Y & 4.1 & $\mathrm{Y}$ & 3.2 & $\mathrm{Y}$ & 15.5 & $\mathrm{y}$ & 13.9 & $\mathrm{Y}$ & 13.6 & Y \\
\hline 20 & 4.4 & $\mathrm{Y}$ & 2.8 & $\mathrm{Y}$ & 3.6 & $\mathrm{Y}$ & 3.3 & $\mathrm{Y}$ & 11.4 & $\mathrm{Y}$ & 10.4 & $\mathrm{Y}$ & 10.2 & $\mathrm{Y}$ \\
\hline
\end{tabular}




\section{REFERENCES}

[1] CHEN, G.P.; LIU F.; et al. A Planning comparison of 7 irradiation Options Allowed in RTOG 1005 for Early-Stage Breast Cancer. Medical Dosimetry. v. 40, pp. 21-25, 2014.

[2] McMAHON, S. J., The linear quadratic model: usage, interpretation and challenges. Physics in Medicine and Biology. v. 64, 0TR01, 2019.

[3] APPELT A.L.; VOGELIUS I.R.; et al. Modern Hypofractionation Schedules for Tangential Whole Breast Irradiation Decrease the Fraction Size-corrected Dose to the Heart. Clinical Oncology. v. 25, pp 147-152, 2013.

[4] JONES B.; DALE R.G.; et al. The Role of Biologically Effective Dose (BED) in Clinical Oncology. Clinical Oncology. v. 13, pp 71-81, 2001.

[5] KOULOULIAS, V.; ZYGOGIANNI, A. Hypofractionated Radiotherapy for Breast Cancer: too fast or too much?. Translational Cancer Research. v. 5, pp 688-693, 2016.

[6] BUDACH, W.; BOLKE, E.; et al. Hypofractionated Radiotherapy as Adjuvant Treatment in Early Breast Cancer. A Review and Meta-Analysis of Randomized Controlled Trials. Breast Care. V.10, pp. 240-245, 2015.

[7] TAYLOR, C.; CORREA, C.; et al. Estimating the Risks of Breast Cancer Radiotherapy: Evidence from Modern Radiation Doses to the Lungs and Heart and from Previous Randomized Trials. Journal of Clinical Oncology. v. 35, pp 1641-1649, 2017.

[8] SOUMAROVÁ, R.; RUSINOVÁ, L. Cardiotoxicity of Breast Cancer Radiotherapy - Overview of Current Results. Reports of Practical Oncology and Radiotherapy. v. 25, pp 182-186, 2019.

[9] MOSAIQ brochure (visited 29/07/21) https://www.elekta.com/dam/jcr:d79cff58-91ce-4d4cb27d-472dc38da371/MOSAIQ-RO-brochure.pdf

[10] KOULOULIAS, V.; GOGALIS, I.; et al. A Unique Hypofractionated Radiotherapy Schedule with 51.3Gy in 18 Fractions Three Times per Week for Early Breast Cancer: Outcomes Including Local Control, Acute and Late Skin Toxicity. Breast Cancer. v. 24, pp 263-270, 2017.

[11] XiO brochure (visited 29/07/21) https://www.elekta.com/dam/jcr:b3948f4a-0ac8-4317-9b8941178a44a670/XiO-Comprehensive-RTP-System-product-brochure.pdf 
[12] BEATOM, L.; BERGMAN, A.; et al. Cardiac Death after Breast Radiotherapy and the QUANTEC Cardiac Guidelines. Clinical and Translational Radiation Oncology. v. 19, pp 3945, 2019.

[13] ZEVERINO, M.; PETERSSON, K.; et al. A Treatment Planning Comparison of Contemporary Photon-based Radiation Techniques for Breast Cancer. Physics and Imaging in Radiation Oncology. v. 7, pp 32-38, 2018.

[14] A Phase III Trial of Accelerated Whole Breast Irradiation with Hypofractionation Plus Concurrent Boost Versus Standard :Whole Breast Irradiation Plus Sequential Boost For Early-Stage Breast Cancer. Principal Investigator: VICINI, F. NRG Oncology, GRTOG 1005, 2014. 